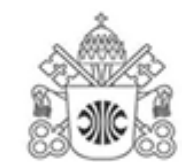 \\ PUC Minas

\section{Análise de Livros Didáticos de Matemática do Ensino Médio: a Presença das Tecnologias Digitais para o Conteúdo de Funções*}

Analysis of High School Mathematics Textbooks: the Presence of Digital Technologies for the Content of Functions

\author{
Júlio Paulo Cabral dos Reis ${ }^{1}$ \\ Neuber Silva Ferreira ${ }^{2}$ \\ Atália Júlio Benedito ${ }^{3}$
}

Guilherme Mendes Tomaz dos Santos ${ }^{4}$

\begin{abstract}
Resumo
$\mathrm{Na}$ atualidade, a utilização das Tecnologias Digitais da Informação e Comunicação (TDIC) como recurso didático para os processos de ensino e aprendizagem, em particular na Matemática, já é uma realidade. Nesse contexto, o objetivo desse artigo foi analisar a presença das TDIC, em sete coleções de livros didáticos do Ensino Médio, no período de 2015 a 2016, referente ao conteúdo de funções: afim, quadrática, exponencial e logarítmica. Tais coleções foram escolhidas com base no catálogo dos livros didáticos para o Ensino Médio, aprovados pelo Plano Nacional do Livro Didático (PNDL) - 2018 e também pela utilização dessas coleções na instituição dos autores. A pesquisa qualitativa, com objetivo exploratória e tendo-se a pesquisa documental como procedimento técnico. Como suporte para analisar os livros, utilizamos os seguintes documentos oficiais nacionais: o Parâmetro Curricular Nacional (PCN), o PCN+e as Orientações Curriculares para o Ensino Médio (OCEM), para a área de matemática. A partir deles, elaboramos uma matriz referência de análise. Tal matriz buscou sumarizar, nos livros, a presença das TDIC e elementos/características para
\end{abstract}

\footnotetext{
* Submetido em 14/04/2020 - Aceito em 18/12/2020

${ }^{1}$ Mestre pelo Programa de Pós-Graduação em Ensino de Ciências e Matemática da Pontifícia Universidade Católica de Minas Gerais - PUC/Minas. Professor no Instituto Federal de Minas Gerais - IFMG Campus Ibirité, Brasiljulio.reis@ifmg.edu.br

${ }^{2}$ Doutor pelo Programa de Pós-Graduação em Ensino de Ciências e Matemática da Universidade Cruzeiro do Sul - UNICSUL. Professor do Instituto Federal de Minas Gerais - IFMG Campus Ouro Preto, Brasil- neuber.ferreira@ifmg.edu.br

${ }^{3}$ Mestranda no Programa de Pós-Graduação em Ciências - Física dos Materiais da Universidade Federal de Ouro Preto - UFOP, Brasil- ataliabenedito@gmail.com

${ }^{4}$ Pós-Doutorando no Programa de Pós-Graduação em Educação da Universidade Federal do Rio Grande do Norte - UFRN. Bolsista PNPD/CAPES, Brasil-mendes.guilherme234@ gmail.com
} 
a utilização dessas no ensino de matemática. Os principais resultados apontaram que, dos sete livros, seis sugerem a utilização de software livre e calculadoras. Nenhum livro menciona a utilização de smartphones e tablets. Constatamos, ainda, que existe uma carência efetiva da presença das TDIC, de modo a indicar uma necessidade de maiores interlocuções didático-pedagógicas para o ensino de funções no Ensino Médio com ferramentas variadas.

Palavras-chave: Educação matemática. Ensino de funções. Tecnologias digitais. 


\begin{abstract}
Nowadays, the use of Digital Information and Communication Technologies (TDIC) as a didactic resource for teaching and learning processes, particularly in Mathematics, is already a reality. In this context, the objective of this article was to analyze the presence of TDIC, in seven collections of high school textbooks, in the period from 2015 to 2017, referring to the content of functions: related, quadratic, exponential, and logarithmic. We chose these collections based on the catalog of high school textbooks, approved by the National Textbook Program (PNDL), and because they are used in the authors' institution. We adopted the qualitative research, with exploratory objective having documentary research as a technical procedure. We use the following official national documents as support to analyze the books: National Curriculum Parameters ( $\mathrm{PCN})$, the Curriculum Guidelines for Secondary Education (OCEM), and PCN+. Based on the documents, we elaborated a reference analysis matrix, which sought to summarize the presence of TDIC in the books, as well as elements/characteristics for their use to teach mathematics. The main results showed that six of the seven books suggest the use of free software and calculators. None of them mentions the use of smartphones and tablets. We also realized a lack of TDIC indicating the need for better didactic-pedagogical interlocutions for teaching functions in high school using various tools.
\end{abstract}

Keywords: Math education. Function teaching. Digital technologies. 


\section{INTRODUÇÃO}

No que diz respeito à educação, tem-se um crescimento gradativo do uso de ferramentas tecnológicas digitais dentro das salas de aula, que busca ligar os estudantes à realidade vivida atualmente. Moran, Masetto e Behrens (2010), relatam que o computador é o símbolo primordial dessa tecnologia, quando se refere ao âmbito educacional. Nesse sentido, utilizar tecnologias digitais no ambiente escolar, possibilita uma educação em que o estudante possa aprender de forma mais autônoma.

Moran, Masetto e Behrens (2010) e Cordeiro e Silva (2015), desenvolveram pesquisas referentes à presença das tecnologias digitais da informação e comunicação - TDIC - nas escolas, obtendo inúmeros relatos relacionados à utilização de variadas ferramentas tecnológicas e suas contribuições, bem como os desafios para potencializar os processos de ensino e aprendizagem. De acordo com esses autores, as TDIC podem contribuir para a construção de conhecimentos, para a compreensão dos alunos em relação aos conteúdos específicos e, inclusive, para a compreensão dos problemas do cotidiano.

Tomando como referência a disciplina de Matemática, essa é conhecida como uma linguagem e suas relações por meio do estudo da Aritmética, Álgebra, Geometria, Tratamento da Informação e outros. Geralmente, acaba sendo entendida pela sociedade do conhecimento como uma ciência complexa, mas fundamentalmente necessária no contexto do ensino-aprendizagem, uma vez que a possibilita na resolução e compreensão de problemas dos mais variados contextos. Nesse sentido, nas últimas décadas, para melhor compreender tal complexidade, a utilização das TDIC no lócus educacional surge como uma estratégia de potencializar uma melhor compreensão e acessibilidade a todos. Conforme apontam Cordeiro e Silva (2015), o ensino de Matemática por meio de um software específico

pode ser bastante eficiente para o desenvolvimento da aprendizagem, bem como algumas vantagens podem ser enumeradas: a elevação do nível de aprendizagem (uma melhor visão de conteúdos abstratos), a junção entre conhecimento e uso da tecnologia e a relação entre conteúdo e prática. (CORDEIRO; SILVA, 2015, p. 9).

Uma forma de inserir as ferramentas tecnológicas nas salas de aula, em particular, do Ensino Médio, é por meio dos livros didáticos - especialmente promovido pelo Programa Nacional do Livro Didático - PNLD (BRASIL, 2018). Esses estão presentes nas escolas e instituições e é um material considerado, pela maioria dos profissionais envolvidos, uma base da composição didática. A tecnologia pode estar presente no livro didático por intermédio de programas computacionais, calculadoras diversas, smartphones, tablets, internet, dentre outros. Dessa forma, pode tornar-se uma ferramenta de auxílio aos professores no seu trabalho pedagógico, possibilitando/potencializando o aprendizado dos estudantes.

Segundo PNLD (BRASIL, 2018), o livro didático deve-se permitir a construção de conhecimentos nos processos de ensino-aprendizagem, possibilitando o desenvolvimento de habilidades e competências nas diferentes áreas do conhecimento - incluindo a Matemática. O 
manual do professor deve-se fundamentar na valorização dos conhecimentos preliminares do aluno além de estar paralelo ao conhecimento científico. Nesse contexto, o livro didático pode favorecer diferentes interações da escola com a família e comunidades, visto que, por vezes, é o principal meio de acesso dessas ao conhecimento científico, especialmente nas que possuem maior vulnerabilidade social. Contudo, quando refletimos sobre a sociedade do conhecimento contemporânea, pensamos que está totalmente conectada e com acesso ao uso de tecnologias. Entretanto, especialmente no Brasil, mesmo sendo sociedade está imersa em um mundo cada vez mais tecnológico, o acesso ainda é um desafio quando olhamos a totalidade da população, visto que cerca de $40 \%$ da população possui computadores com acesso à internet em seus domicílios e 59\% têm smartphones com pacotes de dados (IBGE, 2019).

Visto a importância das TDIC no meio Educacional, este artigo tem por objetivo analisar a presença das TDIC, em sete coleções de livros didáticos do Ensino Médio, no período de 2015 a 2017, referente ao conteúdo de funções: afim, quadrática, exponencial e logarítmica. Buscou-se averiguar o meio com que os autores interligaram ferramentas didáticas relacionadas à tecnologia em suas coleções, de modo a auxiliar o docente, aprimorando a sua prática pedagógica. A presença das TDIC vem como forma de potencializar o estudo da matemática representando-o significativamente de maneira diversificada e unificada. Assim, se torna necessária atentar aos autores e aos docentes sobre a importância da tecnologia para um aprendizado mais significativo, a fim de despertar o interesse discente para o estudo da matemática em geral. O foco dado ao conteúdo de funções se deu em virtude das problemáticas ocorridas no percurso acadêmico dos estudantes.

\section{A UTILIZAÇÃO DA TECNOLOGIA NA EDUCAÇÃO COMO RECURSO DIDÁTICO- PEDAGÓGICO}

$\mathrm{Na}$ atualidade, muito se tem debatido sobre a utilização de novas tecnologias como recurso para auxiliar e/ou complementar os processos de ensino-aprendizagem. Nesse cenário, devido ao avanço tecnológico e as variadas ferramentas existentes, pode-se oferecer uma gama de possibilidades ao profissional docente que tenha interesse em complementar a sua prática pedagógica. Entretanto, Moran, Masetto e Behrens (2010) afirmam que há indícios da falta de uma valorização do uso da tecnologia na educação escolar, pois, estava convicto que o papel da escola era o de "educar" seus alunos interligando o termo "educação" à transmissão de um conjunto organizado e sistematizado de conhecimento.

Um dos fatores que contribuem para a dificuldade de implementação da tecnologia na educação está relacionado ao meio de aprendizagem praticado nas salas de aula, vivido desde as décadas antigas. Nesse, o ensinamento era focado em teorias comportamentais que cobravam dos alunos a autoaprendizagem, embasado em um plano de ensino técnico que tinha como objetivo passar métodos de trabalho aos professores para praticarem com os seus alunos. Era linear e oferecia pouca mobilidade dentre os aspectos listados. De tal modo, que inserir a 
tecnologia se configurava e m algo que fugiria d o padrão ou a té mesmo a lgo que o professor pouco estava preparado para utilizar em suas aulas.

Laudares e Lachini (2001) afirmam que a pedagogia tecnicista é induzida pelo reducionismo tendo como fundamento a premissa de que o centro da eficiência é o material didático, deixando repassar a atuação dos alunos e professores no processo ensino-aprendizagem. Não obstante, as ferramentas tecnológicas nas mãos dos orientadores tornam-se instrumentos para atingir os resultados educacionais. Com esse cenário na educação, temos a atuação de muitos professores profissionais que têm c omo pretensão a lcançar novas metodologias pedagógicas, recursos didáticos diferenciados, entre outros. Tais ações objetivam a busca de estratégias para que se possa levar aos alunos uma educação de qualidade, de modo que eles possam sair da escola motivados a buscar novos conhecimentos, adquirindo um saber maior e diferenciado.

O uso de programas (software), poderá ser empregado como estímulo para a aprendizagem. O meio que os programas devem ser incorporados no currículo escolar, nas atividades realizadas dentro das salas de aula poderá, a nosso ver, promover o sucesso do estudante no seu processo de escolarização. Nessa perspectiva, Carraher, Carraher and Schliemann (2001) sugerem que os professores devam assumir uma postura de arquitetos cognitivos, estimulando a inteligência coletiva ao planejarem suas metas de ação integradas ao uso da tecnologia, a fim de explorarem bem suas potencialidades no trabalho junto aos alunos.

A mudança de postura pedagógica não é uma tarefa fácil para os professores, uma vez que, grande parte deles aprenderam e foram formados pela pedagogia tradicional. Essa mudança exige deles uma preparação mental, de valores e atitudes, possibilitando aos estudantes um desenvolvimento de participação através de diálogos, responsabilidade individual e social, além das habilidades para a aprendizagem no viés tecnológico. Moran, Masetto e Behrens (2010) salienta que o uso da tecnologia no processo de aprendizagem não se trata de uma substituição do quadro e do giz, mas, sim, da inclusão e associação de técnicas que possibilitem o desenvolvimento intelectual e afetivo, de competências e atitudes dos estudantes.

Para que a tecnologia tenha sentido na educação básica é necessária uma adequação dela com o intuito de alcançar os objetivos pedagógicos propostos, buscando-se atingir, por sua vez, a aprendizagem estudantil. O uso da tecnologia na educação pode modificar o comportamento do professor, tornando-o um agente mais mediador e colaborador na díade ensino-aprendizagem. O aprendiz poderá coletar informações, analisá-las em todos os aspectos relacionados à disciplina e discuti-las com os colegas, com o professor e até mesmo com indivíduos externos ao ambiente escolar. A partir dessa troca de comunicação, os estudantes podem gerar conhecimentos significativos para o desenvolvimento cognitivo, ampliando sua visão sobre sua realidade e formação humana e social.

A aceitação das conexões entre a tecnologia e a educação pode acarretar numa correlação do ensino com os aspectos sociopolíticos, econômicos e culturais da sociedade, desde que a instituição educativa e o professor assumam esta intencionalidade para tal ação. Os alunos podem passar a estudar conteúdos científicos mais significativos para a sua vida, ampliando o conhecimento a fim de atingir os seus objetivos, identificando os problemas e solucionando-os. 
Desse modo, a tecnologia quando se fundamenta a uma proposta de educação que tem como objetivo o pensamento crítico e consciente, promove por meio de seus recursos a ampliação do conhecimento. Essa concepção está ligada à prática que proporciona situações de ensino e aprendizagem que envolve recursos e mecanismos metodológicos e inovadores. Todavia, AGUIAR e PASSOS (2014) alegam que se deve propor um planejamento interdisciplinar, apresentando desafios na pretensão de alcançar o conhecimento, estudando a competência das ferramentas didáticas e tecnológicas. Para os autores, a inovação dos materiais pedagógicos, possibilitam a busca pelo saber, permitindo a interação entre a educação, tecnologia e informação.

Nessa direção, no que tange à importância atribuída para a utilização das TDIC - especialmente na área da Matemática - em documentos oficiais da Nação: os Parâmetros Curriculares Nacionais - PCN - (BRASIL, 1998), PCN+ (BRASIL, 2002) e as Orientações Curriculares para o Ensino Médio - OCEM - (BRASIL, 2006) é notória. Para tal apresentamos o Quadro 1 com as principais ideias sobre o tema em foco. Vejamos:

\section{Quadro 1 - Síntese das TDIC em documentos oficiais}

\begin{tabular}{|c|c|c|}
\hline Documento & Comentário & Tipos de Tecnologias Sugeridas \\
\hline PCN - Médio & $\begin{array}{l}\text { A tecnologia vincula-se } \\
\text { ao saber fazer e } \\
\text { pensar no contexto } \\
\text { da matemática. }\end{array}$ & $\begin{array}{c}\text { Rádio, Televisão, Calculadora e } \\
\text { Computador, Vídeos Didáticos, } \\
\text { (Destaque). }\end{array}$ \\
\hline $\mathrm{PCN}+$ & $\begin{array}{l}\text { Impossibilidade de desvincular } \\
\text { as TDIC em pleno século XXI } \\
\text { dos processos de ensino e } \\
\text { aprendizagem em Matemática. }\end{array}$ & $\begin{array}{c}\text { Computador, Calculadora, } \\
\text { Televisão, Vídeos, Aparelhos } \\
\text { de Reprodução de CD's } \\
\text { e/ou DVD’s e até mesmo } \\
\text { Cinema.Além de relatar a } \\
\text { Internet e as Planilhas Eletrônicas. }\end{array}$ \\
\hline OCEM & $\begin{array}{l}\text { Matemática como ferramenta na } \\
\text { compreensão da tecnologia atual. } \\
\text { Tecnologia entendida como } \\
\text { recurso didático-pedagógico. }\end{array}$ & $\begin{array}{l}\text { Planilhas Eletrônicas, Calculadoras, } \\
\text { Software, Computador, } \\
\text { Programas de Expressão. Internet. }\end{array}$ \\
\hline
\end{tabular}

Fonte: Elaborado pelos autores.

Em suma, a partir da leitura dos documentos supracitados, encontramos contribuições da utilização das TDIC como: (a) auxiliar em cálculos mecânicos de forma rápida e eficiente; (b) exploração de representações gráficas e outras representações auxiliando e agilizando o trabalho com variados problemas; (c) motivar os alunos no estudo da Matemática por meio de investigações e explorações; (d) promover atitudes positivas em relação a verdadeira natureza da Matemática - a saber, aplicar conhecimentos matemáticos a contextos diversos; (e) auxiliar no desenvolvimento cognitivo e na autonomia do aluno, pela utilização de programas que levem a pensar, refletir e criar. Com tais contribuições, o convite ao professor para que se utilize as TDIC é apresentado no sentido da criação de condições e possibilidades para que ocorra a inserção delas durante o desenvolvimento do currículo escolar, de forma natural e espontânea. 


\section{ENSINO DE FUNÇÕES E AS TDIC}

O Tema Função é objeto de estudo de muitos pesquisadores em Educação Matemática no Brasil e em outros países, o que constata sua importância para a Matemática. O processo de ensino e aprendizagem desse tema também possui importante relevância no cenário educacional, pois tem sido motivo de investigações no âmbito da Educação Matemática. Também é um dos temas existentes nos documentos oficiais compondo um dos eixos de organização dos objetivos de aprendizagem.

Diante desse contexto, buscamos trazer nesta seção, o aporte teórico sobre o ensino de funções. Como o tema deve ser ensinado? Quais as orientações dos documentos oficiais? Também iremos destacar as potencialidades didático-pedagógicas das TDIC em um contexto do ensino dos conceitos relacionados ao tema Função.

Ao consultarmos a literatura, percebemos nos relatos de alguns pesquisadores (ROSSINI, 2006) que a maneira tradicional e enciclopédica como o conceito de Função tem sido desenvolvida por professores do Ensino Fundamental e Médio, não tem alcançado o objetivo final que, a nosso ver, é a "compreensão do conceito". Ademais, os conceitos relacionados ao tema em tela foram desenvolvidos ao longo do tempo por vários pensadores e esperamos que nossos estudantes tenham o entendimento em algumas aulas.

O fato é que existe por parte de uma parcela representativa de estudantes da educação básica, dificuldades relacionadas às ideias sobre o conceito de função. Definições sobre variável, dependência, regularidade e generalização, são segundo Tinoco (1996), as ideias básicas relacionadas ao conceito de função e que, por vezes, os estudantes apresentam limitações. De acordo com os autores, essas ideias assumem um papel fundamental para a assimilação do conceito de função, sendo então necessário trabalhá-las na educação básica. Tinoco (1996) ainda ponderam que o uso de variáveis para descrever fenômenos de variação, coloca a ideia de variável como central no entendimento do conceito de função. Caraça (1951, p. 128) afirma que a noção de variável é uma das mais difíceis para se compreender devido ao "o caráter contraditório do conceito - a variável é e não é cada um dos elementos do conjunto". A segunda ideia básica é a noção de dependência. Quando conhecemos uma função, temos algum tipo de descrição da maneira como uma grandeza varia dependendo da variação de outra.

A terceira ideia fundamental é a noção de regularidade. De acordo com Rodrigues (2007, p. 40), essa noção "aparece proveniente aos muitos fenômenos que fluem com certos padrões". Caraça (1951, p. 120) enfatiza que "uma das tarefas mais importantes no trabalho de investigação da natureza é a procura de regularidades dos fenômenos naturais". Esses padrões podem ser detectados, estudados sendo possível fazer previsões de etapas que não podem ser observadas. A existência de fenômenos que ocorrem com regularidade, leva à noção de generalização, quarta ideia básica. Segundo Tinoco (1996, p. 6), "a capacidade de generalizá-los é importante e envolve, em geral, alguma abstração".

Em relação ao ensino, Braga (2006) afirma que o conceito de função faz parte dos temas centrais relacionados aos movimentos inovadores de ensino da Matemática. Segundo esse 
autor, desde as primeiras coleções de livros didáticos foram introduzidos conteúdos relacionados ao pensamento funcional. Atualmente os conteúdos relacionados ao pensamento funcional devem estar de acordo com as competências e habilidades propostas nos documentos oficiais que regem o ensino de matemática. De fato, a partir da promulgação da LDB (BRASIL, 1996), o Ensino Médio passou a fazer parte da Educação Básica ${ }^{5}$, propondo um currículo baseado em habilidades e competências e buscando valorizar o contexto do aluno.

Em seguida, os PCN e PCN+ (BRASIL, 1998; BRASIL, 2002) salientam que:

[...] o conceito de função desempenha também papel importante para descrever e estudar através da leitura, interpretação e construção de gráficos, o comportamento de certos fenômenos tanto do cotidiano, como de outras áreas do conhecimento, como a Física, Geografia ou Economia. (BRASIL, 1998, p. 43-44).

Com a devida relevância do documento, a sugestão é que, em competências e habilidades a serem desenvolvidas nesse nível de ensino - o Ensino Médio -, os computadores e calculadoras contribuam de modo que o discente seja capaz de compreender "limitações e potencialidades" (BRASIL, 1998, p. 46) destas ferramentas. Nesse ínterim, é interessante analisar-se o elo ensino de funções e TDIC, uma vez que há sugestões como a incorporação de computadores para a realização de leituras ou assistir a vídeos didáticos, bem como a criação de recursos que auxiliem o processo ensino-aprendizagem.

O uso dessa diversidade é de fundamental importância para o aprendizado porque tabelas, gráficos, desenhos, fotos, vídeos, câmeras, computadores e outros equipamentos não são só meios. Dominar seu manuseio é também um dos objetivos do próprio ensino das Ciências, Matemática e suas Tecnologias. Determinados aspectos exigem imagens e, mais vantajosamente, imagens dinâmicas; outros necessitam de cálculos ou de tabelas de gráfico; outros podem demandar expressões analíticas, sendo sempre vantajosa a redundância de meios para garantir confiabilidade de registro e/ou reforço no aprendizado. (BRASIL, 1998, p. 53).

Muitos dos conceitos e aspectos do conteúdo de função pode ser abordado com a utilização das TDIC, principalmente os supracitados. Nos PCN+, apresentam-se como competências e habilidades para área de matemática:

Compreender formas pelas quais a Matemática influencia nossa interpretação do mundo atual, condicionando formas de pensar e interagir. Por exemplo, comparando os cálculos feitos pelas máquinas com aqueles feitos "com lápis e papel", e identificando a função, especificidades e valores de cada um desses meios na construção do conhecimento. (BRASIL, 2002, p. 118).

Voltados para o ensino-aprendizagem do conteúdo de função, esboços gráficos, cálculos e análises podem ser comparados com a utilização de TDIC. Nesse sentido, de acordo com o referido documento evidenciamos que:

${ }^{5}$ Cabe ressaltar que, desde em 2009 com Emenda Constitucional n. 59 (BRASIL, 2009) e a Lei n. 12.796 (BRASIL, 2013), o Ensino Médio passou a ser uma etapa obrigatória da educação básica, juntamente com a educação infantil, tendo como educação básica obrigatória dos 4 aos 17 anos de idade. 
O crescente uso dos computadores constitui um importante capítulo à parte, pois, além de sua capacidade de edição de textos e organização de dados, abre portas para um universo de informações, com o aprendizado da "navegação" na Internet, permitindo consultar inúmeros bancos de dados e sites informativos e formativos, para não falar dos estimulantes intercâmbios individuais e institucionais. (BRASIL, 2002, p. 136).

Já as OCEM (BRASIL, 2006) trazem como "princípio que toda situação de ensino e aprendizagem deve agregar o desenvolvimento de habilidades que caracterizem o pensar matematicamente". O texto destaca que é preciso priorizar a qualidade do processo em detrimento à quantidade de conteúdo, selecionando assim conteúdos básicos que devem ser trabalhados. Entre esses estão as funções. No que concerne a elas, as OCEM salientam que:

Para o estudo das funções, das equações e das desigualdades da geometria analítica (retas, círculos, cônicas, superfícies), tem-se uma grande variedade de programa de expressão. Em muitos desses programas, pode-se trabalhar tanto com coordenadas cartesianas como com coordenadas polares. Os recursos neles disponibilizados facilitam a exploração algébrica e gráfica, de forma simultânea, e isso ajuda o aluno a entender o conceito de função, e o significado geométrico do conjunto-solução de uma equação - inequação. (BRASIL, 2006, p. 89).

Destaca-se aqui a exploração gráfica por recursos tecnológicos, tais recursos permitem visualizar, investigar, conjecturar, compreender e construir conceitos e conhecimentos relacionados a temática função. Os programas de expressões podem ser compreendidos como software, planilhas eletrônicas dentre outros que permitam a plotagem e reflexão gráficas de funções.

Nesse contexto, seguindo as orientações dos documentos oficiais, entendemos que o ensino da matemática, em especial o ensino de funções, pode ser enriquecido por meio de propostas pautadas no uso de recursos tecnológicos como instrumentos que visam auxiliar a aprendizagem sem anular o esforço da atividade compreensiva. Entendemos, também, que o ensino das funções, diante de todas as questões abordadas, exige uma ação pedagógica que reconheça a dinamicidade e a importância do papel da Matemática na sociedade atual que é repleta de tecnologias.

Sendo assim, no processo de ensino-aprendizagem, a utilização das TDIC podem servir como um recurso pedagógico, pois muitos entendem a tecnologia como um construto social. Corroboramos com este entendimento e acreditamos que as utilizando no ensino de funções podemos ampliar as possibilidades de investigação, pelo favorecimento de características dinâmicas em representações gráficas, geométricas e algébricas.

Dentre as tecnologias mais utilizadas na área da Matemática, destacamos o uso de programas educacionais. Considerados assim programas educacionais a partir do momento em que sejam projetados por meio de uma metodologia que os contextualizem no processo de ensino e de aprendizagem. Estes programas são utilizados em muitos espaços escolares e torna-se, cada vez mais, um amplificador de potencialidades na capitação e aperfeiçoamento dos estudantes, professores e das próprias instituições de ensino. De acordo com Pacheco e Barros (2013), os 
programas matemáticos surgem como alternativa metodológica que amplia os conceitos teóricos dos conteúdos em sala de aula através de recurso dinâmico que pode atrair o interesse e a intuição dos alunos incentivando o estudo dos conceitos de forma inovadora.

Acreditamos que com o uso das ferramentas tecnológicas, como os software, seja possível introduzir as noções básicas necessárias para que o aluno atinja os níveis de compreensão dos conceitos relacionados ao tema função, através de situações cotidianas, simulações, resolução de problemas, ou seja, ensinar os conceitos de maneira investigativa e mais intuitiva. Conforme afirmação de Tinoco (1996), o conceito de função tende a ser mais bem compreendido quando passar por quatro níveis de compreensão: Compreensão Intuitiva; Matematização Inicial; Abstração; Exploração por conjecturas. E com a utilização dos software acreditamos que seja possível propiciar aos alunos condições de evoluírem de um nível de compreensão para outro e adquirirem as noções necessárias para isso, uma vez que tais ferramentas podem facilitar a compreensão, visualização e representação de tais conceitos e conteúdos, tornando a aprendizagem discente mais significativa e contextualizada.

Finalizamos esta seção, afirmando que, conforme os teóricos apresentados, o ensino de funções deve estar em consonância com as tendências educacionais contemporâneas, de forma específica, com o uso de tecnologias para a aprendizagem da Matemática. Sendo assim, entendemos ser relevante uma análise das coleções de livros didáticos aprovados pelo Programa Nacional do Livro Didático (PNLD), na edição denominada PNLD 2018, utilizados no período de 2018 a 2020 quanto à metodologia utilizada para a abordagem de funções, e se essas contemplam a utilização de tecnologias no ensino de função.

\section{PERCURSO METODOLÓGICO}

Esta investigação, pautou-se na abordagem qualitativa, de natureza exploratória, tendose a pesquisa documental como procedimento técnico. A Pesquisa Documental é:

[...] realizada a partir de documentos, contemporâneos ou retrospectivos, considerados cientificamente autênticos (não-fraudados); tem sido largamente utilizada nas ciências sociais, na investigação histórica, a fim de descrever/comparar fatos sociais, estabelecendo suas características ou tendências. (GERHARDT; SILVEIRA, 2009, p. 69).

Para tanto, com base nas diretrizes dos documentos oficiais: PCN (BRASIL, 1998), PCN+ (BRASIL, 2002) e as OCEM (BRAGA, 2006) elaboramos, e apresentaremos na seção 4.2 a seguir, uma matriz com os critérios de análises para alguns livros didáticos.

\subsection{Análises das coleções quanto à temática investigada}

Analisamos, respectivamente, funções polinomiais do $1^{\circ}$ e $2^{\circ}$ graus, exponenciais e logarítmicas. Os livros didáticos foram escolhidos conforme os seguintes critérios: 
(a) Atendendo ao Programa Nacional do Livro Didático (PNLD), que direciona que as coleções devem ser atuais e serem alteradas a cada três anos de uso (todos os livros atendendo o PNLD do ano de $2018^{6}$ );

(b) Pelo encaminhamento das coleções via editoras à instituição no qual dois dos autores trabalham;

(c) Coleções que contemplam os anos de 2015 e 2016;

Diante dos critérios acima elencados, analisamos sete livros didáticos - apresentados no Quadro 2.

\section{Quadro 2 - Síntese das TDIC em documentos oficiais}

\begin{tabular}{|l|l|l|l|l|l|}
\hline Livro & Autor & Título & Edição & Ano & PNLD \\
\hline I & PAIVA, M. & Matemática Paiva & 3. ed. & 2015 & $\begin{array}{c}2018, \\
2019, \\
2020\end{array}$ \\
\hline II & BALESTRI, R. & $\begin{array}{l}\text { Matemática, } \\
\text { Interação \& Tecnologia }\end{array}$ & 2. ed. & 2016 & 2018 \\
\hline III & CHAVANTE E.; PRESTES. & Matemática 1 & 1. ed. & 2016 & 2018 \\
\hline IV & IEZZI, G. et al. & $\begin{array}{l}\text { Matemática: } \\
\text { ciência \& aplicações }\end{array}$ & 9. ed. & 2016 & $\begin{array}{l}2018, \\
2019, \\
2020\end{array}$ \\
\hline V & SOUZA; GARCIA & Contato matemática & 1. ed. & 2016 & 2018 \\
\hline VI & DANTE, L. R. & $\begin{array}{l}\text { Matemática: } \\
\text { contexto \& aplicação }\end{array}$ & 3. ed. & 2016 & 2018 \\
\hline VII & $\begin{array}{l}\text { SMOLE, K. S.; } \\
\text { DINIZ, M. I. }\end{array}$ & $\begin{array}{l}\text { Matemática para } \\
\text { compreender o mundo }\end{array}$ & 1. ed. & 2016 & 2018 \\
\hline
\end{tabular}

Fonte: Elaborado pelos autores (2020).

Conforme podemos observar, no Quadro 2 constam os sete livros didáticos que atenderam aos critérios estabelecidos para a seleção dos materiais e que foram enviados à instituição dos pesquisadores. Nesse sentido, apresentamos a seguir a matriz referente aos critérios de análise dos livros.

\subsection{Matriz de Critério de análise das coleções}

Atendendo aos critérios elencados na seção anterior, buscamos analisar como se deu a abordagem do conteúdo pela utilização da tecnologia no estudo das funções. Procuramos levantar as principais características da utilização destas tecnologias, quando presentes, no livro didático analisado ${ }^{7}$. Ainda, analisamos se a tecnologia foi utilizada de modo a complementar a sequência do livro ou, apenas, como sugestão para o professor.

\footnotetext{
${ }^{6}$ Disponível em: https://www.fnde.gov.br/pnld-2018/

${ }^{7}$ Cabe aqui ressaltar ao leitor que a presença das tecnologias foi analisada no sequenciamento do livro didático discente de forma efetiva. Isto é, descartamos a análise de sugestões de utilização que aparecem somente no
} 
Para facilitar a visualização geral pelo leitor, elaboramos o Quadro 3, no qual consta a codificação dos critérios analisados. Os critérios analisados foram levantados com base nas diretrizes dos PCN, PCN+ e OCEM, no que se refere a área de matemática.

Quadro 3 - Codificação para a análise nos livros didáticos

\begin{tabular}{|c|c|c|c|c|}
\hline \multirow{8}{*}{$\begin{array}{l}\overline{0} \\
\underset{Z}{Z}\end{array}$} & Recursos tecnológicos & \multirow{2}{*}{ Código } & Recursos tecnológicos & \multirow{2}{*}{ Código } \\
\hline & Computador & & Calculadora & \\
\hline & Ambientes virtuais & $\mathrm{AV}$ & Científica & $\mathrm{C}$ \\
\hline & Internet & I & Normal & $\mathrm{N}$ \\
\hline & Jogos & $\mathbf{J}$ & Programável & $\mathrm{P}$ \\
\hline & Planilhas Eletrônicas & $\mathrm{PE}$ & & \\
\hline & Software Específicos & $\mathrm{SE}$ & & \\
\hline & Videoaulas e/ou Vídeos & $\mathrm{V}$ & & \\
\hline
\end{tabular}

Fonte: Elaborado pelos autores (2020).

Nessa perspectiva, a partir do Quadro 3, buscamos compreender a presença das tecnologias segundo a pesquisa realizada. Deste modo, trazemos os elementos analisados, conforme o Quadro 4.

Quadro 4-Análise documental realizada nos livros didáticos segundo os critérios preestabelecidos

\begin{tabular}{|c|c|c|c|c|c|c|c|c|c|}
\hline \multirow{2}{*}{ Livro } & \multicolumn{5}{|c|}{ Computador } & \multicolumn{3}{|c|}{ Calculadora } \\
\cline { 2 - 9 } & $\mathrm{AV}$ & $\mathrm{I}$ & $\mathrm{J}$ & $\mathrm{PE}$ & $\mathrm{SE}$ & $\mathrm{V}$ & $\mathrm{C}$ & $\mathrm{N}$ & $\mathrm{P}$ \\
\hline I & & & & & $\mathrm{x}$ & & $\mathrm{x}$ & $\mathrm{x}$ & \\
\hline II & & $\mathrm{x}$ & & & $\mathrm{x}$ & & $\mathrm{x}$ & & \\
\hline III & & & & & & & $\mathrm{x}$ & & \\
\hline IV & & & & & $\mathrm{x}$ & & $\mathrm{x}$ & & \\
\hline V & & $\mathrm{x}$ & & & & & $\mathrm{x}$ & & \\
\hline VI & & & & & $\mathrm{x}$ & & $\mathrm{x}$ & & \\
\hline VII & & & & & $\mathrm{x}$ & & $\mathrm{x}$ & $\mathrm{x}$ & \\
\hline
\end{tabular}

Fonte: Elaborado pelos autores (2020).

Considerando o Quadro 4, apresentamos os resultados e discussões referentes à análise realizada.

\section{ANÁLISE DOS RESULTADOS}

A exploração no livro I revelou a presença das tecnologias por meio de dois recursos tecnológicos: (a) software livre/gratuito e (b) calculadora. Esse livro apresenta, para os conteúdos elencados, seções denominadas "conectado". Nestas seções, as abordagens foram realizadas manual do professor e/ou outro instrumento que não seja o sequenciamento do livro didático que o discente teria posse nos capítulos dos conteúdos elencados: (a) função afim; (b) função quadrática; (c) função exponencial e (d) função logarítmica. Consideramos de modo efetivo, aquele onde o discente, irá utilizar algumas das tecnologias supracitadas de maneira ativa. 
pelo suporte exclusivo do software Winplot. O autor explica como obter o software ${ }^{8}$ e as ações de utilização do mesmo são voltadas a plotagem/exploração/reflexão de elementos gráficos, em particular, translações e análises de parâmetros.

Alguns exercícios trazidos mencionam o emprego da calculadora normal e científica. A utilização desses recursos tecnológicos está em consonância com a pesquisa de Machado (2008) ao indicar que a tecnologia permite uma simulação que facilita a compreensão dos estudos em diferentes situações, além de possibilitar a construção de relações entre os homens e novos ambientes. Cabe destacar, que a utilização desse recurso tecnológico como suporte a área educacional está muito presente na literatura vigente e nas diretrizes dos documentos oficiais (BRASIL, 2002; BRASIL, 2006). A calculadora é utilizada no livro para explorar exercícios contextualizados, como datação de fósseis, nível sonoro, dentre outros ${ }^{9}$

Importante salientar que a calculadora, também, permite reflexões c omo a obtenção de respostas aproximadas para uma situação-problema. Geralmente, no conteúdo de função exponencial e de função logarítmica, o trabalho com aproximações são importantes para elucidar alguns tipos de potências, a exemplo: $3^{1,7}$. O livro I expõe este trabalho com as aproximações trazendo reflexões importantes como desigualdades, aproximações dentre o utras. Assim, a calculadora não é somente utilizada para resolver/solucionar, mas também para explorar, refletir e analisar aproximações, operações, desigualdades etc.

À luz de Machado (2008, p. 6), acreditamos que, na atualidade, os docentes devem oportunizar aos discentes interpretar e construir os "seus próprios significados, desenvolver capacidades de explorar, formular hipóteses, construir raciocínios lógicos, ter acesso a métodos para resolver situações e problemas não rotineiros". Nessa direção, concordamos com a autora, uma vez que entendemos que tais capacidades podem ser agregadas aos processos de ensino-aprendizagem pela utilização das TDIC. Ressaltamos, ainda, que as TDIC são ferramentas pedagógicas que podem ser utilizadas de formas diversificadas v isando à complementação da práxis pedagógica.

O livro II oferece as TDIC por meio do software livre GeogebraPrim nas seções denominadas "conexão tecnológicas". Antes dos conteúdos analisados nesta pesquisa, Balestri (2016) ensina o passo a passo da utilização do software, bem como o local onde pode ser obtido para instalação, de comandos mais simples a mais complexos, restrição de domínio, por exemplo. O software é indicado para plotagem gráficas, reflexões de gráficos a partir da variação de parâmetros e exploração de elementos ${ }^{10}$. O interessante é que a proposta de ensinar o discente a utilizar o software, bem como a inserção das seções conexão tecnológica ao nosso ver é pertinente, uma vez que, permite a ele, mesmo sem a orientação do professor, explorar o conteúdo com o aporte tecnológico. Nessas seções, por sua vez, há exercícios que podem fazer o discente refletir sobre conhecimentos matemáticos e a plotagem gráfica.

A utilização da calculadora científica s urge n aturalmente, a p artir d a r evisão d e potenciação preparando o campo para o estudo da função exponencial. Bem como realizado com

\footnotetext{
${ }^{8}$ Para os leitores interessados consultar Paiva (2015, p. 165).

${ }^{9}$ O leitor interessado poderá consultar Paiva (2015, p. 224).

${ }^{10} \mathrm{O}$ leitor interessado poderá consultar Balestri (2016, p. 108).
} 
o software, Balestri (2016) deixa claro, textualmente, ao discente os comandos necessários/suficientes para trabalhar com a obra. A presença da calculadora científica fica mais acentuada na unidade de função logarítmica, entretanto, as mais variadas potencialidades não são exploradas. Uma novidade identificada foi no capítulo de função exponencial, pois percebemos o estabelecimento do elo entre função afim/juros simples e função exponencial/juros composto. Ademais, observamos que o autor indica um site onde o discente pode simular investimentos e financiamentos, chamado de Calculadora do cidadão ${ }^{11}$. Essa ação nos parece inovadora no livro didático, visto que os documentos oficiais destacam a utilização da tecnologia por meio da exploração dos instrumentos tecnológicos para possibilitar aos discentes compreender o mundo real, social, econômico e conceitos intrínsecos ao conhecimento matemático. Na função logarítmica, por sua vez, utiliza-se também a calculadora científica para explorar logaritmos decimais e aproximações.

Vários exemplos de aplicações de funções exponenciais e/ou logarítmicas são apresentados pelo autor: (a) lei de resfriamento; (b) crescimento populacional; (c) curva de aprendizagem; (d) elementos radioativos; (e) idade de rochas; (f) dentre outros. Vê-se a contextualização, porém, a utilização das TDIC, nos moldes apresentados, raramente é utilizada para explorar tais aplicações. São mais utilizadas para a plotagem e investigação gráficas de funções dadas nas formas algébricas e análises de aproximações e cálculos. No livro III, identificamos a menção de atividades que exploram calculadora científica e uso de software. Nos capítulos destinados aos conteúdos pesquisados, em uma atividade de função quadrática é solicitada a utilização de algum software, mas não menciona qual e, apenas, sugere-se nesta atividade a plotagem gráfica. Fora dos capítulos relacionados aos conteúdos pesquisados, praticamente no findar do livro, é apontada a planilha eletrônica como recurso tecnológico que permite a plotagem de gráficos. Para tal, apresenta-se o passo a passo para a plotagem de uma única função quadrática, sem exploração ou reflexão. Ao findar o livro apresenta sites onde os discentes podem encontrar vídeos, objetos de aprendizagens dentre outros recursos para, segundo os autores, enriquecerem os seus conhecimentos. Porém, não há menção a qual conteúdo, temática e/ou conhecimentos podem ser construídos pelo acesso ao site. Desse modo, com o relato apresentado, e como a pesquisa procurava analisar a presença das TDIC, utilizadas de maneira ativa nos conteúdos elencados, descartamos o site mencionado como TDIC trazida pelo livro.

A utilização da calculadora é sugerida no capítulo de função exponencial, para auxiliar no cálculo de potências e aproximações (como supracitado nos livros I e II), sem referenciar o modelo, citando apenas que o símbolo para o cálculo pode mudar dependendo do modelo da calculadora. Há uma contextualização, situação-problema sobre terremotos no capítulo de função logarítmica e a indicação de uma atividade que explora distintas maneiras de se utilizar a calculadora ou programas. Por outro lado, não demonstra como fazer tais utilizações para os discentes.

O livro IV utiliza o software gratuito Geogebra, utilizado de maneira básica, apenas para plotagem gráfica, ou seja, uma outra análise superficial. O livro oferece restritas e limitadas

\footnotetext{
${ }^{11}$ Disponível em: https://www3.bcb.gov.br/CALCIDADAO/publico/exibirFormCorrecaoValores.do? method=exibirFormCorrecaoValores. (Acesso em 21/11/2020). Fonte: Adaptado Balestri (2016, p. 142).
} 
atividades para serem desenvolvidas com o aporte desse software. ${ }^{12}$. Nas funções exponencial e logarítmica, a calculadora cientifica é citada como ferramenta para auxiliar os cálculos. Menciona-se o número de Napier ${ }^{13}$. Há uma exibição de como se deve usar algumas teclas da calculadora. Moran, Masetto e Behrens (2010) afirmam que há indícios da falta de uma valorização do uso da tecnologia em educação escolar, pois, o papel da escola era o de "educar" seus alunos interligando o termo "educação" à transmissão de um conjunto organizado e sistematizado de conhecimento. Por conseguinte, notamos que essa desvalorização do uso da tecnologia ainda permanece nas escolas e nos livros didáticos.

O livro IV, ainda, pouco explora as TDIC nos conteúdos analisados. Entretanto, intenta, de certo modo, procurar atender as diretrizes educacionais para este nível de ensino por meio de outras características, como a utilização de situações-problema contextualizados. Importante salientarmos, também, que no manual do professor os autores trazem inúmeros sites e propostas para a utilização das TDIC.

$\mathrm{O}$ livro $\mathrm{V}$, em vários momentos no conteúdo investigado, apresenta propostas contextualizadas complementares aos discentes, relacionando o conteúdo estudado com temáticas pertinentes à formação deles. Durante este processo, sites são indicados com intuito de complementar informações e/ou aprofundar o estudo sobre a temática. Não há indicação de software para explorar atividades. Entretanto, a calculadora é evidenciada em várias atividades e pontos no estudo de função exponencial e função logarítmica. A utilização não difere das já apresentadas anteriormente. Segundo Pacheco e Barros (2013), a utilização dos programas amplia os conceitos teóricos dos conteúdos dados em sala de aula, podendo atrair o interesse dos alunos e, desta forma, incentivando o estudo de conceitos de forma mais inovadora.

No livro VI, o conteúdo de funções traz a seção matemática e tecnologia, software livre como o Libreoffice (por meio das planilhas eletrônicas) e o Geogebra. Esses são apresentados e utilizados como ferramentas para auxiliar na construção e exploração de gráficos, bem como de conceitos de funções (variação de parâmetros, conjunto domínio, conjunto imagem etc.). O livro descreve os programas demonstrando o passo a passo desde a sua instalação, bem como os procedimentos para construção/reflexão dos gráficos nestas seções ${ }^{14}$. Dante (2016) expõe, ainda, a utilização da calculadora científica no capítulo de logaritmos na resolução de uma situação-problema e, durante tal resolução, elucida como o estudante pode utilizar as teclas "log" e "ln". Ainda no capítulo, há evidências de exercícios e situações contextualizadas cuja a resolução é sugerida com a utilização da calculadora científica.

O livro VII tem uma seção denominada "foco na tecnologia" e para o estudo de funções apresenta-se a planilha eletrônica e o software livre, o Winplot. Dentro dos conteúdos elencados, é utilizado o Winplot para construção de gráficos e exploração de semelhanças e di-

${ }^{12} \mathrm{~A}$ indicação da utilização deste recurso tecnológico poderá ser consultada pelo leitor interessado em Iezzi et al. (2016, p. 137).

13،A descoberta do número e é atribuída a John Napier, em seu trabalho de invenção dos logaritmos, datado de 1614 [...]. Nele, Napier introduziu, de forma não explícita, o que hoje conhecemos como número e. Um século depois, com o desenvolvimento do cálculo infinitesimal, o número e teve sua importância reconhecida. O símbolo e foi introduzido por Euler, em 1739." (IEZZI et al., 2016, p. 138).

${ }^{14}$ Uma destas seções pode ser consultada pelo leitor em Dante (2016, p. 83). 
ferenças. As autoras ensinam desde a instalação do software, comandos e oferecem atividades exploratórias dentro desta seção e ainda em outras atividades referente aos conteúdos pesquisados ${ }^{15}$. Nota-se que o livro traz a intersecção Matemática/Tecnologia para os processos de ensino-aprendizagem. Nessa perspectiva, os PCN (BRASIL, 1998), enfatizam que a calculadora e o computador são instrumentos de transmissão da informação e podem contribuir em situações exploratórias e/ou de investigações no ensino da Matemática, bem como a construção de conhecimentos matemáticos.

O livro utiliza, ainda, a ferramenta tecnológica denominada calculadora normal e/ou científica, principalmente na exploração dos cálculos, resolução de atividades, situações-problema contextualizados e compreensão de conceitos. Em uma das seções "foco na tecnologia" as autoras ensinam os estudantes várias funções da calculadora e, também, como realizar cálculos a partir da resolução de atividades contextualizadas.

Em suma, na maioria dos livros didáticos verificamos a presença da tecnologia como suporte pedagógico e não único aos processos de ensino e aprendizagem de Matemática, o que corrobora com documentos oficiais: PCN (BRASIL, 1998), PCN+ (BRASIL, 2002) e OCEM (BRASIL, 2006). Destacamos a utilização de software livre Geogebra, GeogebraPrim e Winplot e menções as planilhas eletrônicas. O modo que são utilizados no conteúdo de funções convergem normalmente para a plotagem gráfica ou reflexões gráficas das funções. Esses, normalmente segregados em seções específicas para interseção tecnologia/matemática. A utilização da calculadora é unânime nas coleções analisadas, e normalmente, é utilizada nos conteúdos de função exponencial e logarítmica.

Deste modo, tais coleções atendem também os profissionais interessados em acrescentar/complementar a sua prática com a utilização das TDIC.

\section{CONSIDERAÇÕES FINAIS}

Retomando a investigação realizada, tivemos como objetivo geral analisar a presença das TDIC em sete coleções de livros didáticos do Ensino Médio, no período de 2015 a 2017, referente ao conteúdo de funções: afim, quadrática, exponencial e logarítmica. Para tanto, nos apoiamos nos documentos oficiais para identificar a presença das TDIC nos livros didáticos. Os documentos centrais foram: PCN (BRASIL, 1998), PCN+ (BRASIL, 2002) e Orientações Curriculares para o Ensino Médio (BRASIL, 2006).

Com a análise dos livros didáticos, pudemos notar que a maioria deles trouxe, de modo ameno ou não, a utilização de alguma TDIC, seja esta por meio de software gratuitos e/ou calculadora científica. A descrição desses programas, no geral é superficial, sem uma abordagem mais aprofundada. Constatamos, ainda, que nenhum dos livros recorreu à utilização dos smartphones e tablets, que no cenário atual da Educação Matemática, pode gerar diversas produções e pesquisas, uma vez que são dispositivos que já fazem parte do dia a dia de grande parte

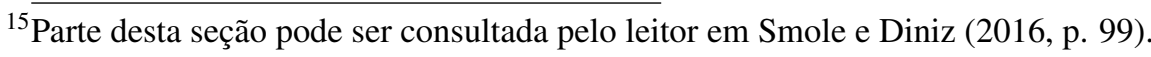


dos alunos da educação básica.

Verificamos que os livros convergem para a utilização das TDIC, em maior ou menor, utilização. Talvez pelo fato de estarem em conformidade pelo PNDL 2018 (BRASIL, 2018) e seguindo algumas das recomendações das diretrizes dos documentos oficiais (BRASIL, 1998; BRASIL, 2002; BRASIL, 2006). Sugestões como videoaulas, ambientes virtuais, vídeos, jogos tecnológicos não foram encontrados em nenhuma das coleções.

Tais evidências nos fizeram refletir sobre a possibilidade de uma abertura de um campo para novas pesquisas no que diz respeito à inserção das tecnologias na Educação Matemática, em especial, por meio dos smartphones, redes sociais, dentre outras, que já despontam educacionalmente como recursos didático-pedagógicos complementares à prática docente. Cabe aqui salientar, que não estamos dando primazia as TDIC, como recurso complementar ou suporte, para o processo ensino-aprendizagem e, sim, buscamos analisar a presença delas nos livros didáticos cabendo, as demais reflexões, aos leitores interessados por esta temática. Não estamos aqui para dizer qual é o livro mais adequado, pois compreendemos que todos eles são, uma vez que todos foram aprovados pelo PNLD 2018. Logo, compreendemos que todos adequam-se às diretrizes educacionais brasileiras. Apontamos aqui a presença das TDIC nas coleções nos capítulos referente aos conteúdos mencionados e como são utilizadas. Também reforçamos a ideia de que elas se configuram em mais uma possibilidade de recurso pedagógico para a educação, não único e exclusivo.

Tais resultados nos gerou uma preocupação, visto que a educação apresentada nas escolas, parece não estar refletindo a realidade atual da sociedade do conhecimento do século XXI - globalizada, híbrida, tecnológica e dinâmica. Ao nosso ver, acreditamos que a tecnologia está ganhando o seu espaço ao redor do mundo e nos diferentes contextos - social, científico, cultural, político, econômico, dentre outros. Contudo, revela-se ser insuficiente no que diz respeito à educação.

Nos parece evidente que, se houver uma intencionalidade pedagógica e uma postura voltada para a inclusão efetiva da tecnologia como aliada ao processo de ensino e aprendizagem, ela pode tornar o conteúdo mais compreensível para os estudantes. Quanto ao ensino de matemática no Ensino Médio, acreditamos que o livro didático, ainda continua sendo uma das ferramentas - se não for a única - mais utilizadas na prática pedagógica do professor. As tecnologias, por ser um novo paradigma no contexto educacional, ainda parece ser um obstáculo para essa disciplina.

No que concerne ao ensino de funções, foi mostrado ao longo do estudo as possibilidades de trabalho docente voltado para a aprendizagem por meio das tecnologias. Contudo, revelamos que esse viés - o tecnológico - ainda está aquém do proposto pelos documentos oficiais. Sendo assim, surge uma necessidade de maior atenção para adequar e estimular esse olhar mais próximo da realidade contemporânea.

À guisa de uma conclusão, acreditamos que estamos muito aquém do desejado para uma educação de qualidade para o ensino de matemática, bem como na aprendizagem desse campo de conhecimento pelo alunado. Todavia, as tecnologias digitais podem tornar-se uma forte 
aliada para a aproximação da(s) realidade(s) dos estudantes, de modo a tornar a matemática mais interessante e acessível ao educando. Nesse sentido, os livros didáticos em conjunto com tais recursos tecnológicos podem ser um meio de transpor barreiras diante da aprendizagem do conhecimento e da linguagem matemática. 


\section{REFERÊNCIAS}

AGUIAR, I. A. de; PASSOS, E. A tecnologia como caminho para uma educação cidadã. Cairu em revista, n. 3, 2014.

BALESTRI, R. Matemática: interação e tecnologia 2.ed. São Paulo: Leya, v. 1, 2016.

BRAGA, C. Função: a alma do ensino da matemática. São Paulo: Annablume, 2006.

BRASIL. Lei de Diretrizes em Bases da Educação Nacional. Estabelece as diretrizes e bases da educação nacional. Brasília: Presidência da República, 1996.

BRASIL. Emenda Constitucional. n. 59, de 11 de dezembro de 2009.

BRASIL. Lei n. 12.796, de 4 de abril de 2013. Altera a lei $n^{\circ} 9.394$, de 20 de dezembro de 1996, que estabelece as diretrizes e bases da educação nacional, para dispor sobre a formação dos profissionais d a e ducação e d ar o utras providências. B rasília: Presidência d a República, 2013.

BRASIL. Ministério da Educação. PNLD 2018: Matemática. Brasília: Ministério da Educação, Secretaria de Educação Básica, 2018.

BRASIL, Ministério da Educação. Parâmetros Curriculares Nacionais: Matemática. Brasília: MEC, 1998.

BRASIL, Ministério da Educação. Parâmetros Curriculares Nacionais +: Matemática. Brasília: MEC, 2002.

BRASIL, Ministério da Educação. Orientações Curriculares Nacionais para o Ensino Médio. Brasília: MEC, 2006.

CARAÇA, B. J. Conceitos fundamentais da Matemática. Lisboa: Sá da Costa, 1951.

CARRAHER D; CARRAHER T; SCHLIEMANN, A. Na Vida Dez Na Escola Zero. 11.ed. São Paulo: Cortez, 2001.

CHAVANTE E.; PRESTES, D. Quadrante Matemática. São Paulo: SM, 2016. v.1.

CORDEIRO, N. J. N.; SILVA, M. N. da. Matemática e Geografia de maneira interdisciplinar: A geometria esférica com suporte do software R. In: Pereira, A. C. C.; Cedro, W. L. Educação matemática: diferentes contextos, diferentes abordagens. Fortaleza: UECE, 2015. p. 13-48.

DANTE, L.R. Matemática: contexto e aplicações. São Paulo: Ática, 2016. v.3.

GERHARDT, T. E.; SILVEIRA, D. T (Org.). Métodos de pesquisa. Plageder. Porto Alegre: UFRGS, 2009. (Série Educação a Distância).

IEZZI, G. et al. Matemática: Ciência e aplicações: Ensino Médio. 9.ed. São Paulo: Saraiva, 2016. v.1.

LAUDARES, J. B.; LACHINI, J. O uso do computador no ensino de matemática na graduação. In: LAUDARES, J. B.; LACHINI, J. (Org.) A prática educativa sob o olhar de professores de cálculo. Belo Horizonte: FUMARC, 2001. p. 68-88. 
MACHADO, R. M. A Visualização na Resolução de Problemas de Cálculo Diferencial e Integral no Ambiente Computacional MPP. Tese (Doutorado em Educação) - Universidade Estadual de Campinas, Campinas, 2008.

MORAN, J. M.; MASETTO, M. T.; BEHRENS, M. A. Novas tecnologias e mediação pedagógica. 17.ed. Campinas (SP): Papirus, 2010.

PACHECO, J. A. D.; BARROS, J. V. O uso de softwares educativos no ensino de matemática. Revista de Estudos Culturais e da Contemporaneidade, n. 8, p. 5-13, 2013.

PAIVA, M. Matemática. 3.ed. São Paulo: Moderna, 2015. v.1.

RODRIGUES, M. U. Narrativas no Ensino de Funções por meio de Investigações Matemáticas. 2007. Dissertação (Mestrado em Educação Matemática) - Universidade Estadual Paulista (UNESP), Rio Claro, 2007.

ROSSINI, R. Saberes Docentes sobre o tema Função: uma Investigação das Praxeologias. 2006. Tese (Doutorado em Educação Matemática) - Pontifícia Universidade Católica de São Paulo, São Paulo, 2006.

SMOLE, K. S.; DINIZ, M. I. Matemática para compreender o mundo. São Paulo: Saraiva, 2016. v.1.

SOUZA, J. R..; GARCIA, J. S. R. Contato Matemática. São Paulo: FTD, 2016. v.1.

TINOCO, L. A. A et al. (Org.). Construindo o Conceito de Função no $1^{\circ}$ Grau. Rio de Janeiro. Universidade Federal do Rio de Janeiro - Instituto de Matemática, 1996. (Projeto Fundão). 